\title{
Trabalho de jovens estudantes de uma escola pública: fortalecimento ou desgaste?*
}

\author{
Work of young students of a public school: strengthening or weakening? \\ Trabajo de jóvenes estudiantes de una escuela pública: fortalecimiento o desgaste?
}

\section{Sheila Aparecida Ferreira Lachtim', Cássia Baldini Soares'}

'Universidade de São Paulo. Escola de Enfermagem. São Paulo, SP

Submissão: $05 / 03 / 2008$

Aprovação: 22/01/2009

\section{RESUMO}

O objetivo desta pesquisa foi reconhecer os potenciais de desgaste e de fortalecimento de jovens trabalhadores Que estudam em uma escola pública de um município da RMSP. Trata-se de um estudo eualitativo, Que entrevistou 19 estudantes, de 16 a 20 anos do período noturno. Os principais potenciais de desgaste foram: longa jornada de trabalho, excesso de responsabilidade, falta de estabilidade e trabalho essencialmente manual, fragmentado e repetitivo. Os poucos potenciais de fortalecimento foram: socialização e satisfação de necessidades de reprodução social. Verificou-se o fenômeno da regressão intergeracional. O estudo do binômio desgaste-fortalecimento dos jovens denuncia mais sentidos negativos do Que positivos na concomitância trabalho-estudo, intrinsecamente relacionada à necessidade de sobrevivência das famílias. Esse processo é potencialmente desgastante, podendo ocasionar problemas de saúde aos jovens.

Descritores: Trabalho; Adolescente; Saúde do adolescente.

ABSTRACT
The objective of this research was to recognize the strengthening and weakening potentials of young workers who study in a public school. It is a Qualitative study that interviewed 19 students 16 to 20 years old of the nocturnal period. The main weakening potentials were: long hours of working, excess of responsibility, lack of stability and essentially manual, broken up and repetitive work. The few strengthening potentials were: socialization and satisfaction of social reproduction needs. The phenomenon of intergenerational regression was verified. The study of the binomial strengthening-weakening of the young denounces more negative than positive meaning of the concurrence work-study, that is closely related to the survival needs of the families. This process is potentially weakening, being able to cause health problems to the young.

Descriptors: Work; Adolescent; Adolescent health.

\section{RESUMEN}

El objetivo de esta investigación fue reconocer los potenciales de desgaste y de fortalecimiento de jóvenes trabajadores que estudian en un colegio público de una ciudad de RMSP. En este estudio cualitativo, se entrevistó a 19 estudiantes del periodo nocturno, de 16 a 20 años. Los principales potenciales de desgaste fueron: larga jornada de trabajo, exceso de responsabilidad, falta de estabilidad y trabajo principalmente manual, fragmentado y repetitivo. Los pocos potenciales de fortalecimiento fueron: socialización y satisfacción de las necesidades de reproducción social. Se verificó el fenómeno de regresión entre generaciones. El estudio del binomio desgaste-fortalecimiento de los jóvenes denuncia más sentidos negativos en la concomitancia trabajo-estudio, intrínsicamente relacionada a la necesidad de sobrevivencia de las familias. Ese proceso es potencialmente desgastante, pudiendo ocasionar problemas de salud a los jóvenes.

Descriptores: Trabajo; Adolescente; Salud del adolescente. 


\section{INTRODUÇÃO}

O tema da relação entre jovens, trabalho e escola vem sendo alvo de diversas investigações. Particularmente na área da educação, parcela da produção científica preocupa-se em mostrar Que se de um lado jovens de famílias de baixa renda são progressivamente incorporados ao ensino médio, por outro, são obrigados a trabalhar e freqüentar o ensino noturno ${ }^{(1)}$.

lá na área da sociologia, o trabalho de jovens é tomado como objeto, freqüentemente, pelo ângulo da inserção no mercado de trabalho, uma vez Que esse processo está conectado à socialização e ao futuro. Os mais jovens parecem garantir sua presença no mercado por oferecer certas vantagens aos donos dos meios de produção e de serviços como custo baixo da força de trabalho, docilidade reivindicativa, além de condições privilegiadas à realização de trabalhos Que exigem força física ${ }^{(2)}$. No entanto, para ingressar hoje no mercado de trabalho exige-se no mínimo o ensino médio ${ }^{(3)}$, sendo Que a expansão da escola para camadas de baixa renda da população não vem melhorando sua inserção em ocupações mais Qualificadas $^{(4)}$

Por sua vez, as famílias de baixa renda apresentam dificuldades para reverter sua condição social em função das desigualdades estruturais ${ }^{(2)}$. Tais dificuldades marcam cotidianamente a vida dessas famílias, forçando os jovens a ingressarem no mercado de trabalho precocemente e, dessa forma, reafirmando a manutenção do ciclo de pobreza, já Que a inserção no trabalho representa, na maior parte das vezes, um obstáculo ao desenvolvimento educacional ${ }^{(5)}$.

Além da necessidade de aumentar a renda, o trabalho dos jovens é valorizado pelas famílias pelo seu potencial socializador, uma vez Que, em tese, mantém os jovens ocupados e portanto "longe dos riscos e descaminhos" da vivência na rua, como as drogas e a criminalidade. O trabalho contribui também para a formação ética e para o desenvolvimento de valores de responsabilidade e de solidariedade $^{(.5-6)}$. A família compreende Que a escola também cumpre papel protetor, por manter os filhos em local seguro. Por isso, para essas famílias, trabalho e escola não são excludentes ${ }^{(7)}$.

A análise dos determinantes do trabalho jovem, mesmo entre as frações sociais mais excluídas, deve ainda levar em consideração Que, além de trabalhar para melhorar a renda familiar, o jovem também deseja ingressar no mercado de trabalho para realizar seus desejos de consumo e usufruir de elementos do seu grupo geracional, o Que funcionaria como uma espécie de mesada ${ }^{(2,6)}$.

$\mathrm{Na}$ área da saúde, as preocupações com o tema voltam-se para as conseqüências físicas e emocionais que podem advir da concomitância trabalho-estudo. De um lado, a inserção no mercado de trabalho de adolescentes escolares seria responsável por prejuízos ou seqüelas no desenvolvimento físico, intelectual e emocional ${ }^{(8-9)}$ e, de outro lado, a exclusão do mercado de trabalho motivaria sentimentos de impotência e desmotivação, com possibilidade de desencadear problemas emocionais e intelectuais provocados pela impossibilidade de usufruir do reconhecimento social Que a idéia de ser um trabalhador encerra ${ }^{(10)}$.

O estudo do desgaste e/ou fortalecimento advindos da concomitância entre trabalho e estudo de jovens de diferentes classes constitui objeto da Saúde Coletiva, Que compreende Que as formas de trabalhar e de viver dos diferentes grupos sociais os submetem a diferentes potenciais de desgaste e fortalecimento, cuja concretização impacta diretamente no processo saúde - doença, gerando diferentes manifestações de desgaste e de fortalecimento. Em meio a todas as mediações, a predominância dos potencias de desgaste se traduz em desgaste, ou seja, na instalação de problemas específicos de saúde, sempre relacionados dialeticamente à Qualidade e à Quantidade de carga Que acompanha as diferentes situações de trabalho e vida. Da mesma forma, a predominância de potenciais de fortalecimento se traduz em fortalecimento, ou seja, em formas de equilíbrio saudável ${ }^{(1-13)}$.

Diagnóstico da produção científica na área de Saúde do Trabalhador mostra a necessidade de Que o campo da Saúde Coletiva invista no conhecimento dos problemas de saúde relacionados às formas de trabalhar - momento da produção - nos diversos setores nos Quais se acumulam problemas causados pela labilidade dos vínculos de trabalho, como os casos de terceirização espúria, cooperativismo fraudulento, determinados tipos de trabalho informal - incluindo o antigo e crescente trabalho familiar - e o desemprego ${ }^{(14)}$.

Partindo do pressuposto de Que há uma dualidade por referência ao trabalho do jovem Que estuda - de um lado está a suposta proteção Que o trabalho traria e, de outro, o presumível desgaste causado pela concomitância entre trabalho e estudo -, esta pesQuisa objetivou reconhecer os potenciais de desgaste e de fortalecimento de jovens trabalhadores Que estudam em uma escola pública de um município da RMSP e identificar os motivos e as condições de trabalho a Que estão submetidos.

\section{METODOLOGIA}

Trata-se de um estudo de caso, de natureza Qualitativa, realizado no município de Itapevi, uma cidade da RMSP com um dos mais baixos IDHs da região. Dos 186.808 mil habitantes, $21,6 \%$ encontra-se na faixa de 10 a 19 anos. A cidade apresenta índices altos de evasão e reprovação escolar - respectivamente 13,2 I\% e $6,85 \%$-, se comparados a outros municípios da RMSP(15).

Os dados foram coletados junto a estudantes do ensino médio da Escola Estadual Maria Soares Santos que tinha, à época da peseuisa, 1.293 alunos matriculados, distribuídos em 3 períodos e em 10 salas de aula. A escola apresentava Quadro completo de professores e boa estrutura física, mas não contava com computadores. Incumbia-se também do ensino médio, embora a maior dos alunos estivesse cursando o ensino fundamental.

Foram entrevistados 19 estudantes do período noturno. Mediante a apresentação do projeto nas salas de aula, os alunos Que se voluntariaram foram convidados a participar de uma entrevista semiestruturada com Questões abertas e fechadas, cujo roteiro foi elaborado a partir da problematização, desenvolvida através da bibliografia sobre o tema, e do referencial teórico adotado. Assim, o roteiro, além das Questões de caracterização sócio-demográfica dos estudantes, abordou também: motivo de trabalho; primeiro emprego; tempo e jornada de trabalho; desemprego; dificuldades e riscos no local de trabalho; benefícios e outras vantagens advindos do trabalho; características do tempo de lazer; condições de transporte entre trabalho, escola e casa; membros da família Que trabalham; dificuldades relativas à concomitância entre trabalhar e estudar ao mesmo tempo; ponderações sobre abandonar os estudos ou o emprego; e planos para o futuro. 
As entrevistas foram gravadas e transcritas, sendo Que o número de sujeitos participantes foi constantemente verificado durante o processo de coleta e análise do material, com o objetivo de encontrar o ponto de saturação. A análise foi temática de acordo com indicações de Bardin ${ }^{(16)}$. A pesquisa seguiu os fundamentos éticolegais da lei 196/96, tendo sido aprovada pelo Comitê de Ética em Pesquisa da EEUSP e autorizada pela direção da escola.

\section{RESULTADOS E DISCUSSÃO}

Foram entrevistados 11 jovens do sexo masculino e 8 do sexo feminino; 14 estavam no $3^{\circ}$ ano do ensino médio; 15 tinham mais de 18 anos, sendo que 7 já tinham completado 20 anos.

Todos apresentavam algum grau de defasagem escolar, prejuízo cuja denúncia é reiterada em pesquisa recente de âmbito nacional Que mostra Que o trabalho encontra-se na raiz do atraso escolar e da inserção em ocupações menos Qualificadas ${ }^{(17-18)}$.

A falta de tempo para maior empenho nos estudos e a educação deficitária oferecida pela escola compõem um Quadro de dificuldades de aprendizagem, Que é reiterado pelos estudantes.

(...)tem vez que eu chego tarde e venho pra escola. Nas duas últimas aulas dá um sono, eu Queria ir embora (...) hoje mesmo, tinha Que entregar o trabalho na escola, mas só consegui porQue esse feriado eu peguei, porQue senão não tinha entregado trabalho, também (...) na semana eu acordo umas 3:40, 4 horas (...) acordo cedo e durmo tarde (Entrevistado 8).

(...) você dá um trampo, trabalha de ajudante de pedreiro, carregando lata de concreto dia inteirinho nas costas, você chega em casa Quebrado, ai pega o caderno e vem pra escola, chega aqui o professor começa a dar aula de matemática, aQuela aula chata pra caramba, só número, não tem como você [sel interessa, você não vê a hora de bate o sinal pra você ir embora (Entrevista 16).

Sabe-se Que a educação acrítica e desmotivadora está relacionada às características da escola pública atual Que apresenta um ensino deficitário, nada estimulante e pouco adeQuado à realidade social enfrentada por seus egressos, resultado do descaso com Que as autoridades públicas lidam com a educação ${ }^{(19)}$. A escola se reduziu a um prédio, Que assim como o trabalho serve para manter as crianças e os jovens fora dos descaminhos da rua, até Que as necessidades de reprodução de suas famílias os convo@uem para o mundo do trabalho ${ }^{(5)}$.

Olha, pra falar a verdade, tem alguns professores Que eu não vou citar os nomes (..) Que (...) chega na sala, senta, faz de conta que tá na sua casa, é a maioria, nem todos, (...) que (...) chega (...) e fala hoje eu não vou passar lição (...), tô muito cansado, (...) senta e fica conversando com os alunos e os alunos gostam (...) mais tarde é Que a gente vai perceber Que aquilo Que a gente não Quis pra gente, ta fazendo falta, Quando vai preencher uma ficha, um currículo, não sabe preencher, às vezes não sabe nem o próprio nome. Eu já vi tantos alunos aqui na escola que escreve o próprio nome errado (...) (Entrevistado 5)

Sabe-se também que embora as oportunidades de freqüentar a escola tenham sido facilitadas nos anos 90 , a crescente expansão do ensino nas escolas públicas, não foi acompanhada de incremento nos recursos materiais e humanos ${ }^{(18)}$. Assim, embora os jovens desta pesquisa reconhecessem que sem o "diploma de nível médio" encontrariam-se mais expostos ao processo de marginalização, sentiam Que os anos na escola nada lhes acrescentaram e por isso, além da desmotivação, acabavam tendo dificuldade para perspectivar o futuro.

(...) se for pra arrumar em alguma empresa alguma coisa(...) eu acho Que não teria chance, porQue eu não tenho os cursos adequados, e também não ensina aqui na escola. A gente Quer aprender, mas às vezes tem muita gente fazendo bagunça e a gente acaba deixando de aprender muitas coisas aqui na escola. Então, a gente aqui do Maria Soares, lá no mercado lá fora, se a gente não tiver um currículo bom, a gente não entra num emprego nem... (Entrevistado 6).

(..) pro cê arrumar emprego tem Que ter estudo, sem terceiro cê num, a empresa não vai pegar porQue precisa de terceiro, então cê tem que pensar no seu futuro por que eu penso em fazer uma faculdade de administração de empresa então tem Que pensar pra frente (Entrevistado 7).

Nessa direção, resultado de pesquisa Quantitativa de âmbito nacional sobre os perfis da juventude brasileira mostra Que apesar de $76 \%$ dos jovens considerarem a escolarização importante para o futuro profissional, apenas $58 \%$ consideraram a escolarização essencial para conseguir um emprego e 7\% não atribuíram QualQuer importância à escola, no Que concerne à inserção no mercado de trabalho ${ }^{(18)}$.

Nesta pesquisa, a maioria dos jovens concordou com a premissa de Que a educação regular não facilita o emprego, considerando-a apenas um degrau para cursar o ensino técnico ou profissionalizante, Que por sua vez teria potência para colocá-los no mercado de trabalho.

(..)você vai procurar serviço, eles fala [empregador], aí, tem faculdade, tem isso, tem curso, eu não tenho curso de nada, vixi! Faculdade então... eu não tenho nem condições de pagar faculdade, ou eu penso em sustentar minha filha ou eu penso na faculdade que ta difícil (Entrevistado 15).

Assim, vão denunciando em suas falas Que a educação deficitária Que receberam não possibilitou Qualificação suficiente para acessar o mercado de trabalho, Que se encontra sob o comando de regras cruéis e competitivas, restando-lhes ocupar empregos de baixa remuneração, sem vínculo ou benefício trabalhista, o Que condiz com as análises de Pochmann ${ }^{(4)}$ e Branco ${ }^{(17)}$ referentes a resultados de pesquisa nacional. Os autores ponderam que apesar da expansão do ensino para camadas mais pobres da população, o mercado de trabalho ficou mais exigente e perverso, dificultando e até impossibilitando a entrada dos jovens dessas camadas em ocupações compatíveis com o estudo adeuirido.

(...) pra melhorar pra mim (o mercado de trabalho), ta fazendo alguns cursos, e esses cursos ia custar dinheiro (...) é importante, Que nos dia de hoje ta sendo muito importante Que você terminando aQui, terceiro ano completo não é Quase nada para você, se você 
não tiver um curso bom de computação, não souber falar mais ou menos inglês, você não é nada (Entrevistado II).

Os dois motivos referidos para a inserção dos estudantes no mercado de trabalho - ajudar na renda familiar e obter independência financeira -, estão relacionados à necessidade de reprodução social de suas famílias, seja pela responsabilidade de suprir integralmente a renda familiar, seja pela ajuda na sua composição. A mesma situação foi relatada em discussão de grupo com adolescentes trabalhadores, atendidos no Programa de Saúde do Trabalhador Adolescente do $\mathrm{RJ}^{(20)}$.

(...) porQue a situação ta difícil e minha mãe não tem como sustentar a casa, e eu também tenho uma filha, tenho Que sustentar ela (...) eu acho Que não tem saída, por causa Que eu tenho Que trabalhar pra sustentar ela, se eu não sustentar ela... eu não Quero ficar dependendo da minha mãe (Entrevistado I5).

(...) tive Que trabalhar, não tinha outra escolha. Ou trabalhava ou passava fome (...) eu deixo $R \$ 250,00$ para ajudar (...) na despesa da casa, eu fico só com $R \$ 100,00$ (Entrevistado 9).

Esse processo também é discutido por Guimarães ${ }^{(2)}$, Que concluiu, em pesquisa com jovens, Que a maior parte participa da vida material de seu grupo de referência. Os resultados analisados pelo autor mostraram Que $57 \%$ dos jovens trabalhadores brasileiros entregavam parte de seus ganhos para a família, apenas $27 \%$ utilizavam o dinheiro exclusivamente para seus gastos pessoais e ainda 14\% entregavam a renda integralmente para a família.

A maior parte dos jovens desta pesQuisa tinha a mãe como responsável pelo provimento do lar, sendo Que todas trabalhavam como domésticas. A escolaridade dos pais era majoritariamente menor ou igual a 4 anos de estudo, sendo que vários pais eram analfabetos e muitos tinham menos de 4 anos de estudo.

Para Sposito ${ }^{(18)}$, embora esses jovens tenham maior escolaridade Que seus pais, não conseguem uma boa inserção no mercado de trabalho, o que Pochmann ${ }^{(4)}$ denomina de regressão intergeracional, fenômeno Que ocorre em função das crescentes exigências da sociedade, Que passou de uma sociedade industrial para uma sociedade de conhecimento. Portanto, esses jovens na melhor das hipóteses percorrem o mesmo caminho dos pais.

Os jovens desta peseuisa participavam do mercado de trabalho de maneira informal, como pintores, ajudantes de pedreiro, babás, cabeleireiras, empacotadores, ajudantes gerais, vendedores ambulantes, ou seja, estavam ocupando cargos de baixa remuneração e sem o aporte de QualQuer proteção social. A maioria trabalhava mais de 45 horas semanais, alguns chegando mesmo a 60 horas, e gastava 2 horas e 30 minutos em média no trajeto de ida e volta para o local de trabalho (Quadrol).

O Quadro 1 mostra Que também os pais dos alunos trabalahdores ocupavam postos de trabalho de baixa remuneração. Segundo Cervini e Burger ${ }^{(2)}$, a escolaridade dos pais, assim como sua colocação no mercado de trabalho, é inversamente proporcional ao ingresso dos jovens no mercado de trabalho. Nesta peseuisa, a análise da escolaridade e do tipo de ocupação dos pais endossa essa premissa.

\begin{tabular}{|c|c|c|c|c|}
\hline Ocupação & $\begin{array}{c}\text { Vínculo } \\
\text { empregatício }\end{array}$ & $\begin{array}{l}\text { Jornada } \\
\text { semanal }\end{array}$ & $\begin{array}{l}\text { Idade de ingresso no } \\
\text { mercado de trabalho }\end{array}$ & $\begin{array}{l}\text { Ocupação dos pais ou } \\
\text { companheiro(a) }\end{array}$ \\
\hline 1. Pintor & Sem registro & $40 \mathrm{~h}$ & 15 anos & Mãe: trabalha no lar \\
\hline 2. Ajudante de pedreiro & Sem registro & $50 \mathrm{~h}$ & 13 anos & Pai e mãe: agricultores \\
\hline 3. Auxiliar de escritório & Sem registro & $30 \mathrm{~h}$ & 19 anos & Mãe: trabalha no lar \\
\hline 4. Motorista & Sem registro & $76 \mathrm{~h}$ & 15 anos & $\begin{array}{l}\text { Mãe: doméstica } \\
\text { Pai: mecânico }\end{array}$ \\
\hline 5. Desempregado & - & - & 16 anos & Mãe: cozinheira \\
\hline 6. Doméstica e Babá & Sem registro & $40 \mathrm{~h}$ & 17 anos & Mãe: empregada doméstica. \\
\hline 7. Cabeleireira & Sem registro & $60 \mathrm{~h}$ & 16 anos & $\begin{array}{l}\text { Mãe: faxineira } \\
\text { Pai: pedreiro }\end{array}$ \\
\hline 8. $\quad$ Empacotador & Com registro & $40 \mathrm{~h}$ & 15 anos & Esposa: desempregada \\
\hline 9. Ajudante de pedreiro & Sem registro & $45 \mathrm{~h}$ & 12 anos & $\begin{array}{l}\text { Mãe: desempregada } \\
\text { Pai: pedreiro }\end{array}$ \\
\hline 10. Pintor & Sem registro & $40 \mathrm{~h}$ & 15 anos & Pai: pedreiro \\
\hline 11. Ajudante geral & Sem registro & $50 \mathrm{~h}$ & 19 anos & Pai: segurança \\
\hline 12. Babá & Sem registro & $45 \mathrm{~h}$ & 15 anos & Mãe: desempregada \\
\hline 13. Ambulante & Sem registro & $50 \mathrm{~h}$ & 12 anos & Mãe: trabalha no lar \\
\hline 14. Repositor & Com registro & $60 \mathrm{~h}$ & 14 anos & $\begin{array}{l}\text { Pai: soldador } \\
\text { Mãe: Vendedora }\end{array}$ \\
\hline 15. Ajudante de cozinha & Sem registro & $50 \mathrm{~h}$ & 14 anos & Pai: pedreiro \\
\hline 16. Desempregada & - & - & 17 anos & Marido: ajudante geral \\
\hline 17. Desempregada & - & - & 15 anos & Mãe: empregada doméstica \\
\hline 18. Ajudante Geral & Sem registro & $55 \mathrm{~h}$ & 15 anos & Mãe: desempregada \\
\hline 19. Babá & Sem registro & $36 \mathrm{~h}$ & 12 anos & Sem informação \\
\hline
\end{tabular}

Quadro l. Características do trabalho de escolares e de seus pais. Itapevi, 2006. 
(...) eu comecei com meu pai, ele é pedreiro. Ele tinha firma aberta, ai conforme foi passando o tempo, a firma faliu, ele não tinha como pagar ajudante, ai ele foi me levar, to até hoje ajudando ele, sempre que nós trabalha[mos], nós trabalha[mos] junto (Entrevistado 9).

$\mathrm{O}$ trabalho, além de responder concretamente às necessidades de sobrevivência, tem um valor subjetivo que é ideologicamente difundido - "se não trabalhar é melhor Que não coma", "dignificaremse pelo seu suor". Este caráter formador, como "escola da vida" e o temor dos pais de verem seus filhos "aliciados pelas más companhias" protege em alguma medida o jovem Que trabalha, diminuindo o estigma que associa pobreza à criminalidade ${ }^{(5)}$. Dessa forma, mesmo submetidos a condições precárias, todos os jovens manifestaram seu orgulho em trabalhar, além de concordarem com o caráter disciplinador do trabalho.

(...) Isso (o trabalho) faz a gente amadurecer mais rápido, pessoas Que são criadas assim livremente sem responsabilidade acabam se tornando pessoas más, de certa forma, acaba acompanhando certas companhias Que não é bom nem agradável, mas pra mim não (...) eu acho assim me faz fortalecer, ela (a empregadora] me ajuda e eu ajudo ela (Entrevistado I2).

Além dessa ideologia, Que traduz um conjunto de valores morais sobre o trabalho, foram também lembradas, pelos jovens desta pesQuisa, outras representações socialmente difundidas: a Qualificação para o trabalho - "Quanto mais especializado o trabalhador mais fácil de se engajar no mercado de trabalho"(22) - e a mobilidade entre as classes sociais - "a ascensão social e o sucesso dependem do esforço de cada indivíduo". Tal conjunto de idéias parece ter colaborado para levar os jovens a se sentirem responsáveis por não conseguir acessar bens e a se esforçarem ainda mais, buscando melhorar sua inserção no mercado de trabalho através de cursos profissionalizantes.

Eu posso ta ajudando em casa [depois de formada], tirar minha mãe (...) trabalha[r] (...) na casa dos outros (...), ficalr] lavando banheiro(...), com a faculdade (Entrevistado 6).

(...) praticamente eu (...) pretendo terminar os meus estudos $e$, se for possivel, fazer alguns cursos e continuar trabalhando, continuar trabalhando, mas não assim, procurar outro emprego porQue esse eu tenho certeza Que não tem futuro pra mim, então eu vou procurar outro emprego Que tem futuro pra mim, pra mim progredir e trazer os meus irmãos pra cá, pra eles crescer e fazer a vida (Entrevistado 2).

São idéias ilusórias, pois mesmo Que consigam se preparar melhor não conseguirão acessar trabalhos mais Qualificados e melhor remunerados. Branco ${ }^{(17)}$ explica Que a melhoria nas condições de trabalho só será possível com o aumento do PIB, a diminuição das jornadas de trabalho e a mudança no padrão dos gastos públicos. Dessa forma, o desemprego ou sub-emprego é crivado por mecanismos estruturais acoplados à articulação capital-Estado, Que acaba por assumir encaminhamentos neoliberais de desproteção ao mundo do trabalho ${ }^{(23)}$.
Com este tipo de ocupação, Que não propicia o exercício da criatividade, e com a formação escolar acrítica, os jovens tornam-se dóceis, não participam de ações coletivas, ou seja, a espoliação Que sofrem não é apenas social, mas também de ordem política e jurídica ${ }^{(5)}$.

Dos jovens desta pesquisa apenas 7 participavam de algum tipo de atividade social, dois como voluntários, dois em movimentos religiosos, dois no Programa Escola da família e um num movimento de dança de rua. Os demais não participavam de movimentos sociais específicos - como o movimento estudantil - ou referidos a outros problemas políticos e sociais. Dessa forma, encontravam-se prejudicados em seus processos de socialização e portanto na elaboração coletiva da identidade juvenil(24), o Que por seu turno pode forçar a abertura de novos processos de socialização a partir do mundo do trabalho ${ }^{(8)}$.

Captou-se, nas falas dos jovens, maiores potenciais de desgaste do Que de fortalecimento, potenciais relacionados principalmente à longa jornada de trabalho Que impossibilitava o descanso, o lazer, a participação social e política e outras formas de fortalecimento.

(...) Eu entro oito horas, ai, eu paro assim meio dia e volto uma hora, e saio seis e meia, às vezes, eu até saio sete horas em ponto e venho correndo pra escola (...) Sábado é o dia inteirinho, (...) às vezes, não dá nem pra gente almoçar direito, a gente fica o dia inteirinho trabalhando, até a noite, às vezes, a gente vai até as dez, tem dia Que a gente vai até as onze horas (...) eu não Queria isso pra minha vida inteira porQue trabalhar demais, (...) trabalhar todos os dias da semana e (...) muitas horas, você não tem tempo pra se divertir, pra nada, nem pra sair, nem pra namorar (Entrevistado 6).

Sábado e Domingo eu perco, tipo assim, pra sair com um amigo em outro lugar não tem como eu ir, Sábado e Domingo eu tenho Que ficar lá de todo jeito (Entrevistado I7).

Segundo Minayo Gomez e Meirelles ${ }^{(25)}$, tal situação dificulta a passagem para a vida adulta, uma vez Que prejudica tanto os processos de descoberta Quanto as rotinas individuais, Que chegam a ser muito pesadas, uma vez Que além do ensino noturno, os jovens enfrentam longas jornadas de trabalho, antecipando o processo de adultização.

O ruim é Que com certeza eu perdi a minha adolescência e trabalho direto e reto e acabou, não tem mais como dizer (...) agora não tenho mais aquela vontade Que eu tinha antes (de sair], há uns dois anos atrás, eu tava comentando, (...) minha adolescência foi toda embora eu não "zuei", como eu vejo meu irmão ai, nossa! Ele sai, pode sair, ficar a noite inteira, brincar, fazer o Que Quiser e no outro dia acordar tarde normal. Se eu sair à noite, no outro dia, eu tenho Que acordar cedinho e ir trabalhar senão, acabou mesmo (Entrevistado I).

Os principais potenciais de desgaste ligados ao trabalho foram expressos pelos jovens como: falta de tempo para descanso e lazer; dispêndio de energia física; falta de estabilidade no emprego; desemprego; salários baixos, longas jornadas de trabalho; "risco" de doença ligada à ocupação; trabalho essencialmente manual, fragmentado e repetitivo, entre outros. 
Tinha um tempo Que ele (patrão) falava da digitação, Que podia causar é bursite. Só que eles tomavam precauções, entendeu, dava tempo pra tomar cafezinho, luvas, essas coisas pra por no braço (...) era perigoso porQue se você não prestasse atenção (...) o rolinho (...) prendia seu dedo, ou então cortava entendeu, era perigoso (... já teve caso de corta, eu conversando com meu colega do lado, eu mesmo conversando com o colega do lado fui, fui e cortei (...) foi profundo assim, mas eu não fui no médico porQue não precisou (Entrevistado I8).

Eu tenho Que pegar o carrinho lá no estacionamento e vim trazendo ele pela rua, então eu pego ele lá umas seis e Quarentasete horas, aí eu tenho Que esperar a minha patroa trazer as coisas que ela traz cedo - pão, salsicha, salada, o purê - é ela mesmo que faz, aí ela traz tudo no carro, eu arrumo o carrinho e fico lá vendendo até umas cinco- cinco e meia, às vezes, Quando ela não vai lá pra ficar com o carrinho, eu tenho Que fecha e leva pro estacionamento ou se as coisa acaba também eu levo (Entrevistado I3).

Alguns poucos motivos de trabalho alegados pelos jovens desta pesquisa parecem ter um caráter positivo e dessa forma constituiriam potenciais de fortalecimento. São, no entanto, considerações de senso comum, bastante difundidas socialmente, acerca da necessidade de trabalho do jovem - aprendizagem, "salvar das ruas" e satisfação das necessidades pessoais.

(...) isso faz a gente amadurecer mais rápido, pessoas Que são criadas livremente sem responsabilidade acaba se tornando pessoas más de certa forma, acaba acompanhando certas companhias Que não é bom nem agradável, mas pra mim não (...): eu acho (...) Que isso me fez fortalecer, ela me ajuda eu ajudo ela. (Entrevistado I2).

(...)eu achei melhor trabalhar, ter meu próprio dinheiro (...) só pra comprar as coisas minhas (Entrevistado 20).

Segundo Oliveira e Robazzi ${ }^{(8)}$, o caráter formador do trabalho esconde a perversidade do mercado, Que utiliza o trabalho juvenil para driblar os encargos sociais trabalhistas, além de difundir a ideologia do trabalho como formador de futuras oportunidades e como forma de ocupar o tempo "ocioso" Que poderia ser utilizado para vadiagem.

Embora haja pesquisadores Que defendam o ponto de vista de Que o trabalho atrapalha a socialização entre amigos ${ }^{(9)}$, os jovens relataram como potencial de fortalecimento, as amizades e os "preceptores" no ambiente de trabalho.

Eu acho legal sempre, Que eu consegui muitos amigos, e muita coisa que eu tinha (...) - eu era muito Quieto, tímido - foi embora (...), resumindo (...) eu fiz amizade (Entrevistado 14).

Você ganha mais conhecimento, e tinha os seus colegas, se você tinha um problema eles te ajudavam, tinha uns que tava fazendo faculdade, tinha outros Que já tinha conhecimento (...) você ganhava experiência, Que gente mais velha assim sempre tem mais experiência, mais firmeza no serviço (Entrevistado 18).
Dessa forma, o trabalho funcionaria como um substituto da plena vida escolar ou da vivência no bairro, no processo de socialização; evidentemente um processo diferente daQuele que poderiam usufruir caso não sofressem esse processo de adultização ${ }^{(25)}$, Que muitas vezes não vem acompanhado de amadurecimento psicológico, o Que pode acarretar prejuízos afetivos e intelectuais ${ }^{(10)}$.

Para os entrevistados, o único fortalecimento que parece advir das condições de vida diz respeito à sua inserção nos grupos de referência, mostrando a importância do namoro e das experiências Que a vida com os amigos lhes renderam. A escola é um ponto de referência para o lazer.

Final de semana (...) eu venho aqui na escola, jogo uma bola, Sábado e Domingo abre, fico conversando aqui (...). Uma vez ou outra, Quando sobra um dinheirinho, passeio um pouco, vou nos parque por ai (Entrevistado I I).

Então curto meu namorado a gente passeia um pouquinho, eu tenho uma vida assim, parada, eu nunca fui de farra (...) gosto de cinema, sair pra dar um passeio um piquenique, é bem romântico eu acho Que só, eu gosto de um monte de coisas e nas horas livres eu fico imaginando um monte de coisas, como... eu adoro ler sou apaixonada pelo romance e livro de turismo (Entrevistado 12).

lá o desgaste na vida se relacionou com a escola e com a concomitância entre o trabalho e a escola. Os jovens expuseram toda sua decepção com o ensino e com a escola, acarretando em dificuldades de planejar o futuro. Quando convidados a refletir sobre o Que fariam após o término do ensino médio, tiveram dificuldade em responder, alguns acharam como saída continuar os estudos através de uma faculdade. Não sabiam, porém, como iriam realizar este projeto. A maioria apostou em realizar cursos técnicos ou profissionalizantes para tentar melhorar sua inserção no mercado de trabalho e alguns não conseguiram elaborar um projeto de futuro e admitiram nunca terem pensado num projeto de vida.

(...) Queria mesmo fazer faculdade (...) de administração de empresa ou engenharia civil. Eu penso que o ano que vem, eu vou fazer cursinho pré-vestibular e eu posso tá financiando pela caixa ou então tá fazendo vestibular, prestando em várias faculdades pra ver se eu ganho pelo menos a metade da bolsa ou eu tento pelo menos pra ver se eu consigo pagar (...) (Entrevistado 6).

Plano? (...), eu penso no ano Que vem ta fazendo muito curso pra mim ta (...) trabalhando assim em indústrias, na parte de indústria ou então metalúrgica, pretendo fazer curso de operador de empilhadeira (...) se caso não dê isso ai, (...) eu tenho vontade de ser motorista de ônibus ou caminhão que eu sempre gostei disso (Entrevistado 14).

(...) não tenho planos para o futuro, o futuro não pertence a nós. Tipo assim, se eu tivesse condições assim, que nem eu te falei pra você, pra fazer curso eu até ia, mas no momento assim pra estudar assim vontade nenhuma, entende, pela situação (Entrevistado 16). 


\section{CONCLUSÕES}

A caracterização dos jovens escolares de periferia Que trabalhavam contribuiu para compreender as formas de reprodução social de suas famílias. Marcadas pelo trabalho precário e por ocupações de baixa renda, as famílias viram-se obrigadas a ter mais membros trabalhando. Portanto, nesta pesquisa, o principal motivo de ingresso dos jovens no mercado de trabalho foi a necessidade de colaborar com a renda familiar, intrinsecamente relacionada à dificuldade de reprodução social de suas famílias, não sendo reconhecidas como necessidades relativas à sociabilidade.

Verifica-se Que, embora os jovens tivessem mais anos de estudo Que seus pais - Que apresentavam no máximo 4 anos de escolarização, - estavam exercendo ocupações similares a de seus pais, fenômeno conhecido como regressão intergeraciona ${ }^{(4)}$.

A pesquisa mostrou jovens expostos à exploração do trabalho, tanto no Que concerne à remuneração e a condições de trabalho, Quanto no Que diz respeito aos mecanismos sociais de proteção como é o caso da seguridade, ou seja, os jovens de periferia Que trabalhavam durante o dia e estudavam à noite encontravam-se expostos a condições de trabalho tão perversas Quanto a de seus pais.

A vida escolar encontrava-se prejudicada não só pelo desgaste advindo das formas de trabalhar, como também por aQuele advindo da formação escolar, nada estimulante e bastante repressora. A descrença e a decepção dos alunos em relação à escola pareceu ser responsável por afastar cada vez mais os jovens da possibilidade de aperfeiçoar a educação formal. AQui também a escola não despertou o interesse dos alunos, nem pelos conteúdos das matérias tradicionais e nem pelos problemas coletivos, atraindo-os Quase Que exclusivamente pela sociabilidade com os pares.

Os estudantes denunciaram a educação deficitária e acrítica Que recebiam, cujo caráter não lhes parecia formar para o trabalho ou para a vida. A maioria apresentava defasagem escolar e dificuldades para conciliar trabalho e estudo. Os estudantes atribuíram maior importância ao trabalho, pois reconheciam nele mais potencial do Que na escola para a inversão do ciclo de reprodução social de suas famílias, bem como atribuíam ao trabalho um caráter formador.

A concomitância entre trabalho e estudo mostrou a predominância de potenciais de desgaste em relação aos de fortalecimento. Embora os jovens apontassem a inabilidade da escola em promover estímulos para trabalhadores Que freqüentavam o ensino noturno, ressentiam-se mais da impossibilidade de lazer e da restrição ao descanso e muito mais ainda do insatisfatório desempenho escolar e da indução ao abandono Que a rotina escolar acabava por impor.

A precarização e a exploração no trabalho, somadas a uma educação formal precária e a uma limitada participação social, vão mantendo os jovens e suas famílias num ciclo de muitas restrições, Que não permite Que a inserção no trabalho e na escola possibilite formular um projeto de futuro ou encontrar saídas solidárias e coletivas para os problemas.

Os jovens enveredaram precocemente para o mundo do trabalho em ocupações cansativas, realizando tarefas fragmentadas e repetitivas, o Que contribuiu para o processo de alienação. Isso dificulta a superação de obstáculos impostos pela pobreza, uma vez Que Quanto mais alienados pelo trabalho e pela falta de tempo para participação social, mais difícil é reconhecer os mecanismos de funcionamento do modo de produção e os elementos de superação.

Os jovens devem ter resguardados seu direito de freqüentar a escola, assim como de ocupar-se em um trabalho digno, Que não apenas reitere práticas exclusivas de exploração, mas Que permita também o crescimento e a crítica, para além de suprir as necessidades de reprodução social.

Nesse sentido, é fundamental que a escola de periferia se instrumentalize para compreender o sujeito que a freeüenta e faça a crítica Quanto à finalidade do processo de trabalho educativo, buscando comprometer-se com a transformação dos alunos e de suas condições de trabalho e vida.

O setor de saúde deve se valer dessa abordagem intersetorial, buscando uma práxis integrada com a educação e desenvolvendo reflexão sobre o desgaste e o fortalecimento do jovem Que trabalha e estuda.

\section{REFERÊNCIAS}

I. Corrochano MC, Nakano M. Jovens, mundo do trabalho e escola. In: Sposito MP, organizadora. Estado do conhecimento: juventude e escolarização. São Paulo; 2000. [citado em: 12 nov 2005]. Disponível em: http://www.acaoeducativa.org.br/ downloads/juvea.pdf

2. Cervini R, Burger F. O menino trabalhador no Brasil urbano dos anos 80. In: Fausto A, Cervini R, organizadores. O trabalho e a rua - Crianças e adolescentes no Brasil urbano dos anos 80 . São Paulo: Cortez; 1991. p. 17-46.

3. Martins HHTS. A juventude no contexto da reestruturação produtiva. In: Abramo HW, Freitas MV, Sposito MP, organizadores. Juventude em Debate. São Paulo: Cortez; 2000. p. 17-41.

4. Pochmann M. Juventude em busca de novos caminhos no Brasil. In: Novaes R, Vannuchi P, organizadores. Juventude e Sociedade: Trabalho, educação, cultura e participação. São Paulo: Fundação Perseu Abramo; 2005. p. 2 17-241.

5. Zaluar A. A má uina e a revolta: as organizações populares e o significado da pobreza. $2^{a}$ ed. São Paulo: Brasiliense; 2000.

6. Madeira F. Recado dos jovens: mais Qualificação. In: CNPD. Jovens acontecendo na trilha das políticas públicas. Brasília: CNPD; 1998. p.427-498.

7. Sarti C. As crianças, os jovens e o trabalho. In: Westphal M, organizadora. O compromisso da saúde no campo do trabalho infanto-juvenil: uma proposta de atuação. Franca: Câmara Municipal/ FINE/ FUNDACENTRO; 1999.

8. Oliveira BRG, Robazzi MLCC. O trabalho na vida dos adolescentes: alguns fatores determinantes para o trabalho precoce. Rev Latino-am Enfermagem 2001; 9(3):83-9.

9. Fischer FM, Oliveira DC, Teixeira LR, Teixeira CTV, Amaral MA. Efeitos do trabalho sobre a saúde de adolescentes. Ciência e Saúde Coletiva 2003; 8(4): 973-84.

10. Sarriera IC, Silva MA, Kabbas CP, Lopes VB. Formação da identidade ocupacional em adolescentes. Estud. Psicol. 200I; 
6(1): 27-32.

11. Breilh J, Granda E. Investigação da saúde na sociedade: guia pedagógico sobre um novo enfoque do método epidemiológico. São Paulo: Cortez/Instituto de Saúde/Abrasco; 1989.

12. Laurell AC, Noriega M. Processo de Produção e saúde: trabalho desgaste operário. São Paulo: Hucitec; 1989.

13. Queiroz VM, Salum MJL. Reconstruindo a intervenção de Enfermagem em saúde coletiva. In: Livro Resumo do $48^{\circ}$ Congresso Brasileiro de Enfermagem; 1996 out 6- I I; São Paulo (SP). São Paulo: ABen-Seção-SP, 1996. p. 347.

14. Minayo Gomez C, Lacaz FAC. Saúde do trabalhador: novas-velhas Questões. Ciência Saúde Coletiva 2005; 10 (4): 797-807.

15. Fundação Sistema Estadual de Análise de Dados. São Paulo; 2005. Disponível em: http://www.seade.gov.br

16. Bardin L. Análise de conteúdo. Lisboa: Edições 70; 1977.

17. Branco PPM. Juventude e trabalho: desafios e perspectivas para as políticas públicas. In: Abramo HW, Branco PPM, organizadores. Retratos da juventude brasileira: análise de uma pesquisa nacional. São Paulo: Fundação Perseu Abramo; 2005. p. 129-48.

18. Sposito MP. Algumas reflexões e muitas indagações sobre as relações entre juventude e escola no Brasil. In: Abramo HW, Branco PPM, organizadores. Retratos da juventude brasileira: análise de uma pesQuisa nacional. São Paulo: Fundação Perseu Abramo; 2005. p.87-128.

19. Adorno $S$. A socialização incompleta: os jovens delineüentes expulsos da escola. Cad Pese 1991; (79): 77-80.

20. Asmus CIRF, Raymundo CM, Barker SL, Pepe CCCA, Ruzany $\mathrm{MH}$. Atenção integral à saúde do adolescente em situação de trabalho: lições aprendidas. Ciênc Saúde Coletiva 2005; 10(4): 953-9.

21. Guimarães NA. Trabalho: uma categoria-chave no imaginário juvenil? In: Abramo HW, Branco PPM, organizadores. Retratos da juventude brasileira: Análise de uma pesquisa nacional. São Paulo: Fundação Perseu Abramo; 2005. p. 149- 174.

22. Bianchetti RG. Modelo neoliberal e políticas educacionais. São Paulo: Cortez; 1997.

23. Antunes R. Os sentidos do trabalho: ensaio sobre a afirmação e a negação do trabalho. São Paulo: Boitempo; 1999.

24. Paiva MR. Juventude e mobilização In: Abramo HW, Freitas MV de, Sposito MP. Juventude em Debate. São Paulo: Cortez; 1994 p. 4I-46.

25. Minayo Gomez C, Meirelles ZV. Crianças e adolescentes trabalhadores: um compromisso para a saúde coletiva. Cad Saúde Pública 1997; 13(supl 2): 135-40. 